\title{
$\mathrm{AR}$ 모델 기반의 고전영화의 긁힘 손상의 자동 탐지 및 복원 시스템 설계와 구현
}

\author{
한 녹 손
}

요 약

\begin{abstract}
오래된 영화 필름이나 비디오 테이프 등의 영상물에서 나타나는 대표적인 손상으로는 긁힘과 얼룩무늬 손상이 있으며, 본 논문은 긁힘 손상 을 자동 탐지하고, 자기상관 (AR: autoregressive) 이미지 생성모델 (PAST-PRESENT 모델) 기반의 영상 인페인팅 모델을 사용하여 손상을 복원하는 시스템을 설계하고 구현하였다. AR 이미지 모델 생성을 위해, 지역성을 최대화할 수 있도록 인접 화소를 모으는 Sampling Pattern을 사용하였으며, 추출된 화소들을 필터링 (filtering)하는 단계, AR 모델 파라미터 계산 (model fitting)을 위한 Durbin-Levinson 알고리즘, 최종 파라미터를 통한 훼손된 화소의 예측 및 보간 단계로 구성된다. 구현된 시스템은(1) VHS 테이프를 통한 아날로그 영상물의 디지털화, (2) 긁힘 손상의 자동탐지와 자동손상복원, (3) 얼룩무늬의 수동탐지와 자동복원의 3 단계 복원절차를 지원하도록 설계하였다. 단계 1 과 단계 2 는 영상복 원 고속화를 위해 TIDSP 보드 (TMS320DM642 EVM)을 이용하여 구현하였으며, 단계 3은 사용자의 수동탐지를위해, PC 를 사용하여 구현하 였다. 본 논문에서 제안된 기법을 고전 한국영화 2편 (자유만세와 로보트 태권 $\mathrm{V}$ )에 대하여 실험하였으며, 본 논문에서 제안한 자기상관 기반 의 복원 시스템은 Bertalmio 인페인팅 기법과 비교하였으며, 주관적 화질 (MOS 테스트) 및 객관적 화질 (PSNR), 특히, 숙련된 복원기술자에 의한 복원과의 차이를 정의하는 복구품질 (RR)에서 향상된 결과를 보임을 확인하였다.
\end{abstract}

키워드 : 영상복원, 자기상관, 긁힘 손상

\section{Design and Implementation of AR Model based Automatic Identification and Restoration Scheme for Line Scratches in Old Films}

\author{
Ngoc Soc $\mathrm{Han}^{\dagger} \cdot$ Seong Whan Kim${ }^{+\dagger}$
}

\begin{abstract}
Old archived film shows two major defects: line scratch and blobs. In this paper, we present a design and implementation of an automatic video restoration system for line scratches observed in archived film.We use autoregressive (AR) image model because we can make stochastic and specifically autoregressive image generation process with our PAST-PRESENT model and Sampling Pattern. We designed locality maximizing scanning pattern, which can generate nearly stationary time-like series of pixels, which is a strong requirement for a stochastic series to be autoregressive. The sampled pixel series undergoes filtering and model fitting using Durbin-Levinson algorithm before interpolation process. We designed three-stage film restoration system, which includes (1) film acquisition from VHS tapes, (2) simple line scratch detection and restoration, and (3) manual blob identification and sophisticated inpainting scheme. We implemented film acquisition and simple inpainting scheme on Texas Instruments DSP board TMS320DM642 EVM, and implemented our AR inpainting scheme on PC for sophisticated restoration. We experimented our scheme with two old Korean films: "Viva Freedom" and "Robot Tae-Kwon- $\mathrm{V}^{\prime \prime}$, and the experimental results show that our scheme improves Bertalmio's scheme for subjective quality (MOS), objective quality (PSNR), and especially restoration ratio (RR), which reflects how much similar to the manual inpainting results.
\end{abstract}

Keywords : Inpainting, Restoration, Autoregressive, Line Scratch

\section{Introduction}

Due to physical problems in repeated projection or

† 정 회 원 : 한국전자통신연구소 연구원

† 정 회 원 : 서울시립대학교 컴퓨터과학부 부교수(교신저자)

논문접수 : 2009년 8월 11일

수 정 일 : 1 차 2009년 11 월 26일

심사완료 : 2009년 11월 27일 playback or simply the chemical decomposition of the original material, films are typically degraded. However the need of preservation of those materials had been neglected until recently with the appearance of digital visual media. And there have been increasing awareness of old films preservation. In order to preserve and exploit this material, these degradations must be removed so that 
the picture quality can be restored. However manual retouching large amount of data is impractical, therefore there have been many researches on sophisticated algorithms for automatic restoration the old films. Notably, Bertalmio introduced the concept of digital inpainting in SIGGRAPH 2000 [1] opening the search on effective automatic restoration scheme.

In this paper, we design and implementation of a video restoration system of line scratches and blobs for old films. Our scheme's contribution is that we introduce AR model for image inpainting by using locality maximizing scanning pattern and optimal parameter estimation for missing pixel prediction. The paper is organized as follows. We present two kinds of main film degradations and related researches in section 2 as well as addressing the problem. Section 3 shows details of our video restoration scheme with our designed autoregressive model inpainting. Section 4 shows experiment results with Korean old films using proposed scheme. Section 5 concludes with future research directions.

\section{Related Works}

At the International Broadcast Convention held in Amsterdam, September 2002, there were not less than nine companies presenting solutions for automated digital restoration: Philips, Thomson, Diamant, DaVinci, Silicon Graphics, Apple, Discreet, Snell and Wilcox, and MTI. Projects such as AURORA and BRAVA funded by the $\mathrm{EU}$ are other examples of this increasing interest. And the most recent active project in the large scale is PrestoSpace [2] supported by Euro Union. It aims at providing technical solutions and integrated systems for a complete digital preservation of all kinds of audio-visual collections. Also in Korea, Korean Film Archive (KOFA) is now keeping thousands of Korean films produced before 1990s. KOFA started digital film restoration in 2007.

Line scratches are common degradations of old films caused by the abrasion of the film material during film transport or the developing process. They consist of long, vertical lines of bright or dark intensity, oriented more or less vertically over much of the image. By energy approach, authors in [3] generalized the Kokaram's model [4] using width and height features of the line profile along with Weber's law to test scratches visibility of the image. It was based on the analysis of a mono-dimensional function of image brightness and produces a fast and almost completely automatic algorithm
In the digital world, inpainting (or digital inpainting, also known as image interpolation or video interpolation) refers to the application of sophisticated algorithms to recover lost or corrupted parts of the image data. In another words, inpainting, the technique of modifying an image in an undetectable form, is as ancient as art itself. The notion of digital inpainting was first introduced in the paper by Bertalmio et al. SIGGRAPH 2000 [1]. Since first introduced in the paper by Bertalmio, there has been much effort on this area that now can be classified in three big categories in terms of fundamental problem, what image is. Specifically, each category follows describe the way we try to describe and simulate the process generating digital images:

- Physical simulation: Images are generated by simulating the underlying physical, chemical, or biological processes.

- Random fields: Images are modeled as samples drawn from statistical framework.

- Function spaces: The deterministic approach is to employ appropriate function spaces to calibrate image regularities.

In physical simulation approach, images are generated by simulating the underlying physical, chemical, or biological processes. It is first introduced by Bertalmio et al, on SIGGRAPH 2000 [1] and improved by several researches. Oliveira with Fast Digital Image Inpainting [6] and Telea with Fast Marching Method [7] aimed at improving the inpainting execution time. However the restoration quality is not as good as Bertalmio's results. Ko [8] proposed an inpainting scheme using Sobel operator to estimate isophotes, the scheme is fast and produces nearly identical results as Bertalmio's scheme, however, it leads worse results for the fine detailed or texture regions where Sobel operator cannot produce principal isophote components. Bertalmio described isophotes (line of equal gray value) to propagate information inward damaged region from the boundaries. The method works as follows. First, the image regions to be inpainted are selected. Next, color information is propagated inward from the region boundaries, i.e., the known image information is used to fill in the missing areas. In order to produce a perceptually plausible reconstruction, an inpainting technique here should attempt to continue the isophotes as smoothly as possible inside the reconstructed region. In other words, the missing region should be inpainted so that the inpainted gray value and gradient 
extrapolate the gray value and gradient outside this region. In (Fig. 1), propagation direction $\vec{N}$ as the normal to the signed distance to the boundary $\partial \Omega$ of the region $\Omega$ to be inpainted.

In random field approach, we model images as samples drawn from certain random fields. The primary goal of random field modeling is to understand the probability distribution function $p(u)$, especially when $\Omega$ is a matrix of digital pixels. Classical models are mostly inspired by Gibbs fields in statistical mechanics, in which local energy constraints are imposed as in Ising crystals. A. Kokaram presented a statistical framework for filling in missing gaps in images but just limitedly successful with texture [9]. The algorithm however can also be used as a fallback mode in treating missing data for video sequence reconstruction. The author used a Bayesian approach to repose 2D Autoregressive Models as generative models for texture (using Gibbs sampler) given surrounding boundary conditions. Function space approach is a deterministic approach which employs appropriate function spaces to calibrate image regularities, measured in some energy $E[u]$.

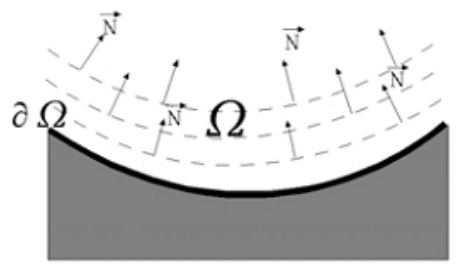

(Fig. 1) Bertalmio's idea of smoothness information propagation

\section{Design of Autoregressive Inpainting Scheme}

We designed the three MODE restoration system using our proposed autoregressive inpainting scheme for Texas Instruments DSP board TMS320DM642 Evaluation Module

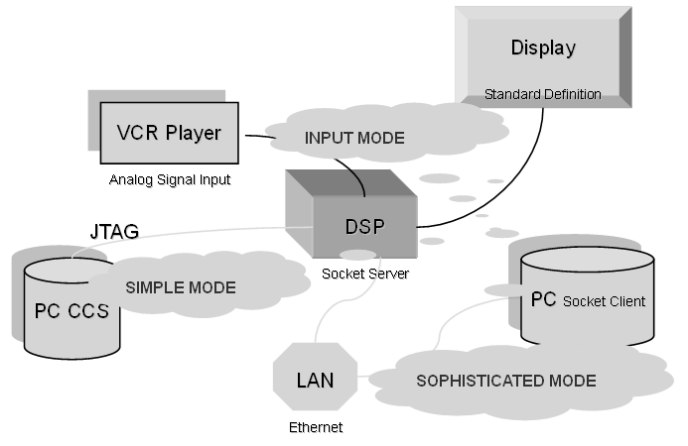

(Fig. 2) System architecture
(EVM) [12] as shown in (Fig. 2).

Autoregressive processes have been used as an effective time series analysis for forecasting. Based on the time series analysis presented in [13], we designed an autoregressive image model for effective interpolation. First consider grayscale images (or 8-bit gray-level images). Each pixel has gray value between 0 and 255 and each grayscale image is the mapping of pixel coordinates into intensity values over a discrete 2-D square region consisting of an $N \times N$ regularly spaced lattice. A PAST-PRESENT model is applied for image with any pixel of the image, there are two distinct regions: one includes pixels with smaller horizontal and vertical coordinates, denote $P A S T$, the other is current pixel, denote PRESENT. Specifically, with the pixel $(m$, $n)$ we define two regions $\operatorname{PAST}(m, n) \operatorname{PRESENT}(m, n)$ as follows:

$$
\begin{aligned}
& \operatorname{PAST}(m, m)=\{(i, j) \mid i<m, j=n\} \cup\{(i, j) \mid j<n\}, \\
& \operatorname{PRESENT}(m, n)=\{(m, n)\}
\end{aligned}
$$

From that point, our model will use the pixels in PAST regions as a sample for estimating underlying image generation process, specifically the autoregressive process. However, instead of using entire PAST region, we use only the sampling region $R_{M}(m, n)$ of PRESENT (current pixel) with the size $M$ (set to 3).

$$
\begin{gathered}
R_{M}(m, n)=\{(m-k, n-l) \mid(1 \leq k \leq M, 0 \leq l \leq M) \\
\cup(-M<k \leq 0,1 \leq l \leq M)\}
\end{gathered}
$$

A raster-type scan (specified later) is used here for pixel sampling that generating one dimensional series of data (pixel) assuming under an autoregressive model. It will be assumed that the intensity $X(m, n)$ of the pixel with horizontal coordinate $\mathrm{m}$ and vertical coordinate $n$, is related to a subset of the past pixels by the equation.

$X(m, n)=\sum_{(m-k, n-l) \in R_{M^{\prime}}(m, n)} \phi(k, l) X(m-k, n-l)+w(m, n)$

Our scheme is to reach the stationarity of pixel series in order to apply forecasting techniques in time series. The entire 3-phrase interpolation process is described in block diagram shown in (Fig. 3) as follows:

[Phase 1] Pixels sampling (sampling observations) and Data Filtering: This is preprocessing phase which converts raw pixel data to the form of auto-regression process. To simulate auto-regressive process, we use 1-D sampling pattern which maximizes locality. Raw data after being collected is not applicable for time series 


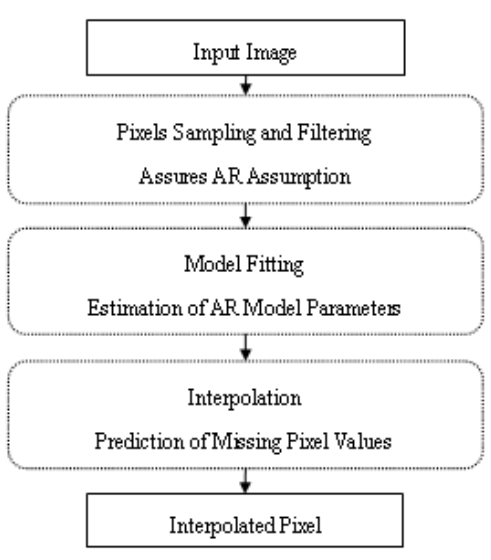

(Fig. 3) AR inpainting block diagram

technique and it is required to be preprocessed by meancorrected filter.

[Phase 2] Model Fitting (parameters estimation): In model fitting parameters of theoretical time series model are estimated with Durbin-Levinson and ARAR algorithm.

[Phase 3] Interpolation: The final phrase focuses on interpolation of unknown pixels by using forecasting techniques. Forecasting functions with prediction operator is applied with DL algorithm.

In our model, we use the pixels in PAST region to estimate parameters for autoregressive process. However, instead of using entire PAST, we only use the sampling region $R_{M}(m, n)$ of PRESENT (current pixel) with the size $M$. We assume that the intensity $X(m, n)$ can be derived from the past pixels. 1-D sampling pattern as shown in (Fig. 4) is used for sampling $M(2 M+1)$ pixels in sampling region that are reordered as an observation set $\left\{x_{t}, t=1 \ldots n\right\}$ where $n=M(2 M+1)$. AR process is assumed under this data set $\left\{X_{t}\right\}$. Then the model is rewritten as

$$
X_{t}=\phi_{1} X_{t-1}-\phi_{2} X_{t-2}-\ldots-\phi_{p} X_{t-p}+\epsilon_{t},
$$

where $p$ is the degree of the model $\operatorname{AR}(p)$.

We applied Simple filter (mean-corrected series): Given pixels $\left\{X_{t}, t=1, \ldots n\right\}$, the mean-corrected pixels are

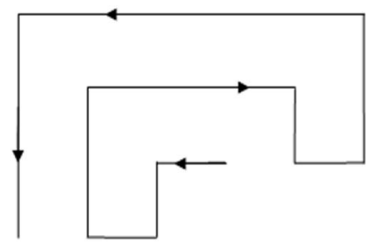

(a)

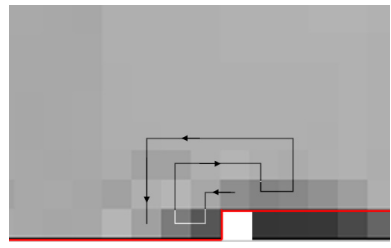

(b)
(Fig. 4) (a) 1-D Sampling pattern, (b) Pixel sampling determined by $\widetilde{X}_{t}=X_{t}-\bar{X}$ where $\bar{X}=\frac{1}{n} \sum_{t=1}^{n} X_{t}$. Pixels are assumed to be generated by $A R(p)$ series: $X_{t}-\phi_{1} X_{t-1}-\phi_{2} X_{t-2}-\ldots-\phi_{p} X_{t-p}=\epsilon_{t}$. From the Phase 2 , a stationary series $\left\{X_{t}\right\}$ with mean $\mu$ were filtered to be a zero-mean series defined by $\widetilde{X}_{t}=X_{t}-\mu$, which is a zero-mean stationary time series. We should make the necessary adjustments for the mean if we wish to predict a stationary series with nonzero mean. The Equation (4) can be written in explicit as

$$
\left[\begin{array}{ccccc}
1 & r_{1} & \ldots & r_{p-2} & r_{p-1} \\
r_{1} & 1 & \ldots & r_{p-3} & r_{p-2} \\
\ldots & \ldots & \ldots & \ldots & \ldots \\
r_{2} & r_{p-3} & \ldots & 1 & r_{1} \\
r_{p-1} & r_{p-2} & \ldots & r_{1} & 1
\end{array}\right]\left[\begin{array}{c}
\phi_{1} \\
\phi_{2} \\
\ldots \\
\phi_{p-1} \\
\phi_{p}
\end{array}\right]=\left[\begin{array}{c}
r_{1} \\
r_{2} \\
\ldots \\
r_{p-1} \\
r_{p}
\end{array}\right]
$$

where $r(h)=c(h) / c(0)$ is sample autocorrelation function, $c(h)=\frac{1}{n} \sum_{t=1}^{n-k}\left(x_{t+h}-\bar{x}\right)\left(x_{t}-\bar{x}\right), \quad(0 \leq h \leq n) \quad$ is sample autocovariance function, $\bar{x}$ is sample mean of observed pixels $\bar{x}=\frac{1}{n} \sum_{t=1}^{n} x_{t}$ with $n=M(2 M+1)$. We use DurbinLevinson algorithm to estimate coefficients $\phi_{0}, \phi_{1}, \ldots, \phi_{n}$ Durbin-Levinson Algorithm (DL) [13] utilizes recursive idea to solve the Equations (5) that is if a time series is an autoregressive process with degree of $p$ then it is also an autoregressive process with degree of $k, k \leq p$. In practical computation, autocorrelation functions are replaced by sample autocorrelation functions $c(k)$ from that $\mathrm{DL}$ algorithm can be expressed in Equations (6)

$\phi_{11}=\frac{c(1)}{c(0)}, v_{0}=c(0)$

$\phi_{k k}=\frac{1}{v_{k-1}}\left[c(k)-\sum_{j=1}^{k-1} \phi_{k-1, j} c(k-j)\right]$

$\left[\begin{array}{c}\phi_{k 1} \\ \cdots \\ \cdots \\ \phi_{k, k-1}\end{array}\right]=\left[\begin{array}{c}\phi_{k-1,1} \\ \cdots \\ \cdots \\ \phi_{k-1, k-1}\end{array}\right]-\phi_{k k}\left[\begin{array}{c}\phi_{k-1, k-1} \\ \cdots \\ \cdots \\ \phi_{k-1,1}\end{array}\right]$

$v_{k}=v_{k-1}\left(1-\phi_{k k}^{2}\right) \quad k=2,3, \ldots, p$

where $\phi_{11}=\gamma(1) / \gamma(0)$ and $v_{0}=\gamma(0), \gamma(k)$ is autocorrelation function. The estimation of model coefficients is $\left\{\phi_{1}=\phi_{p 1}, \phi_{2}=\phi_{p 2}, \ldots, \phi_{p}=\phi_{p p}\right\}$. The simple filter used in phase 2 of data filtering gives a mean corrected series $\widetilde{X}_{t}=X_{t}-\bar{X}$, where $\bar{X}=\frac{1}{n} \sum_{t=1}^{n} X_{t}$. Then the subset AR model for the mean-corrected series $\left\{\widetilde{I}_{t}\right\}$ can be expressed 
as $\phi(B) \widetilde{B}_{t}=\epsilon_{t}$, where $\epsilon_{t} N W N\left(0, \sigma^{2}\right)$ and $\phi(B)=\phi_{1} B$ $-\phi_{2} B^{2}-\ldots-\phi_{p} B^{p}$ which is the polynomial backward shift operator. From that we obtain $\phi(B) X_{t}=\phi(1) \bar{X}+\epsilon_{t}$ Assuming that the fitted model (3-11) is appropriate and that the white noise term $\epsilon_{t}$ is uncorrelated with $\left\{X_{j}\right.$, $j<t\}$ for each $t$, we can determine the minimum mean squared error linear predictors $P_{n} X_{n+h}$ of $X_{n+h}$ in terms of $\left\{1, X_{1}, \ldots, X_{n}\right\}$, for $n>p$, from the recursions

$$
P_{n} X_{n+h}=-\sum_{j=1}^{p} \phi_{j} P_{n} X_{n+h-j}+\phi(1) \bar{X}, h \geq 1
$$

with the initial conditions $P_{n} X_{n+h}=X_{n+h}$ for $h \leq 0$.

\section{Analysis and Experimental Results}

Experimental set-up is shown in (Fig. 5). Digital signal input device (VHS) connects to input video port (composite video) using RCA cable. DSP board connects to LAN through Ethernet interface and to PC via JTAG to download program from Code Composer Studio IDE. An output device (TV Monitor) connects to output video port through RCA cable. For our implementation, we use TMS320DM642 EVM which is a development board with the DM642 Digital Media Processor. TMS320DM642 features a highly integrated on-chip peripheral set which includes PCI interface.

We used two Korean old films "Viva Freedom" (1946) (Fig. 6) and "Robot Taekwon V" (1976) (Fig. 7). The films were converted into $720 \times 480$ YUV video formats in INPUT MODE before going through inpainting process. There are many degradations in form line scratches and blobs in the digitalized videos.

We measured PSNR (peak signal to noise ratio). Higher PSNR does not necessarily imply a higher

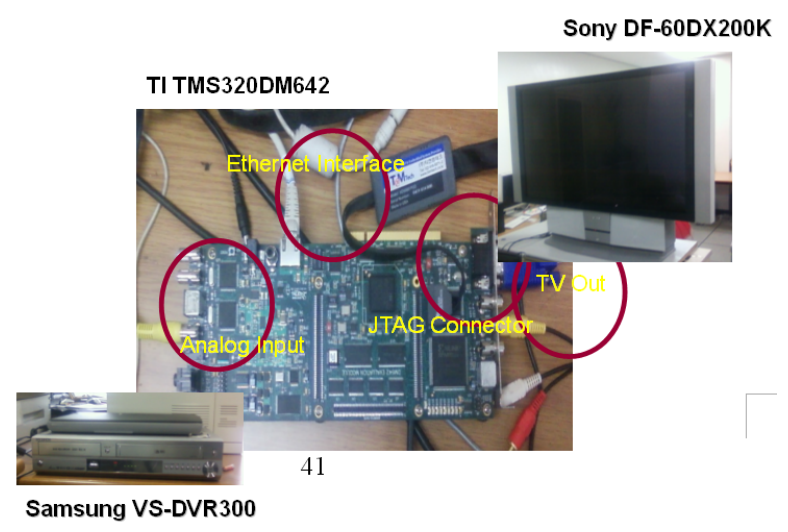

(Fig. 5) Hardware setup in laboratory subjective reconstructed image quality; however they do provide some measure of relative quality. We also used MOS (mean opinion score) test which measures the subjective perceived quality of the frames. In voice and video communication, quality usually dictates whether the experience is a good or bad one. Besides the qualitative description we look, MOS gives a numerical indication of the perceived quality of the media. MOS is expressed in one number, from 1 to 5,1 being the worst and 5 the best. MOS is quite subjective, as it is based on what is perceived by people during tests. To evaluate how similar between our inpainting scheme and artificial inpainting by technicians, we define RR (restoration ratio) as

$$
R R=100 \times \frac{\text { no of retored pixels }}{\text { no of scrached pixels }}
$$

RR measures how many pixels are restored (pixel values differ more than 1 after restoration) among the intentionally scratched pixels.

\subsection{Experimental Results in SIMPLE MODE}

We select 32 frames from main scenes of Viva Freedom and Robot Taekwon V (16 for each film) for our experimentation. We set artificially (manually) restored frame as reference frame, and compare PSNR and Restoration Ratio with the restored frames using our scheme. $<$ Table $1>$ shows PNSR and RR results from all 32 test frames in two films. (Fig. 8) and (Fig. 9) show the restoration result after line scratch removal.

〈Table 1〉 Experimental results in SIMPLE MODE

\begin{tabular}{|c|c|c|c|c|}
\hline Films & \multicolumn{2}{|c|}{ Viva Freedom } & \multicolumn{2}{c|}{ Robot Taekwon V } \\
\hline Frame \# & PSNR & RR & PSNR & RR \\
\hline 1 & 31.55 & 15.40 & 34.70 & 20.30 \\
\hline 2 & 36.40 & 23.51 & 44.52 & 41.65 \\
\hline 3 & 35.42 & 18.56 & 46.12 & 31.69 \\
\hline 4 & 32.60 & 12.61 & 39.49 & 37.10 \\
\hline 5 & 31.77 & 15.52 & 41.73 & 40.16 \\
\hline 6 & 38.09 & 21.58 & 37.08 & 36.27 \\
\hline 7 & 35.35 & 18.76 & 47.10 & 36.82 \\
\hline 8 & 29.73 & 16.83 & 41.69 & 38.47 \\
\hline 9 & 35.57 & 24.98 & 48.25 & 48.29 \\
\hline 10 & 35.30 & 26.80 & 46.44 & 46.55 \\
\hline 11 & 36.58 & 30.08 & 37.77 & 36.66 \\
\hline 12 & 34.22 & 21.56 & 41.01 & 40.67 \\
\hline 13 & 10.28 & 1.23 & 38.35 & 38.12 \\
\hline 14 & 30.63 & 17.48 & 41.35 & 41.76 \\
\hline 15 & 36.19 & 19.97 & 43.66 & 43.88 \\
\hline 16 & 30.27 & 09.26 & 28.13 & 09.61 \\
\hline
\end{tabular}

\subsection{Experimental Results in SOPHISTICATED MODE}

We use 32 selected frames from two films Viva Freedom and Robot Taekwon $\mathrm{V}$ for experiments. Blob 

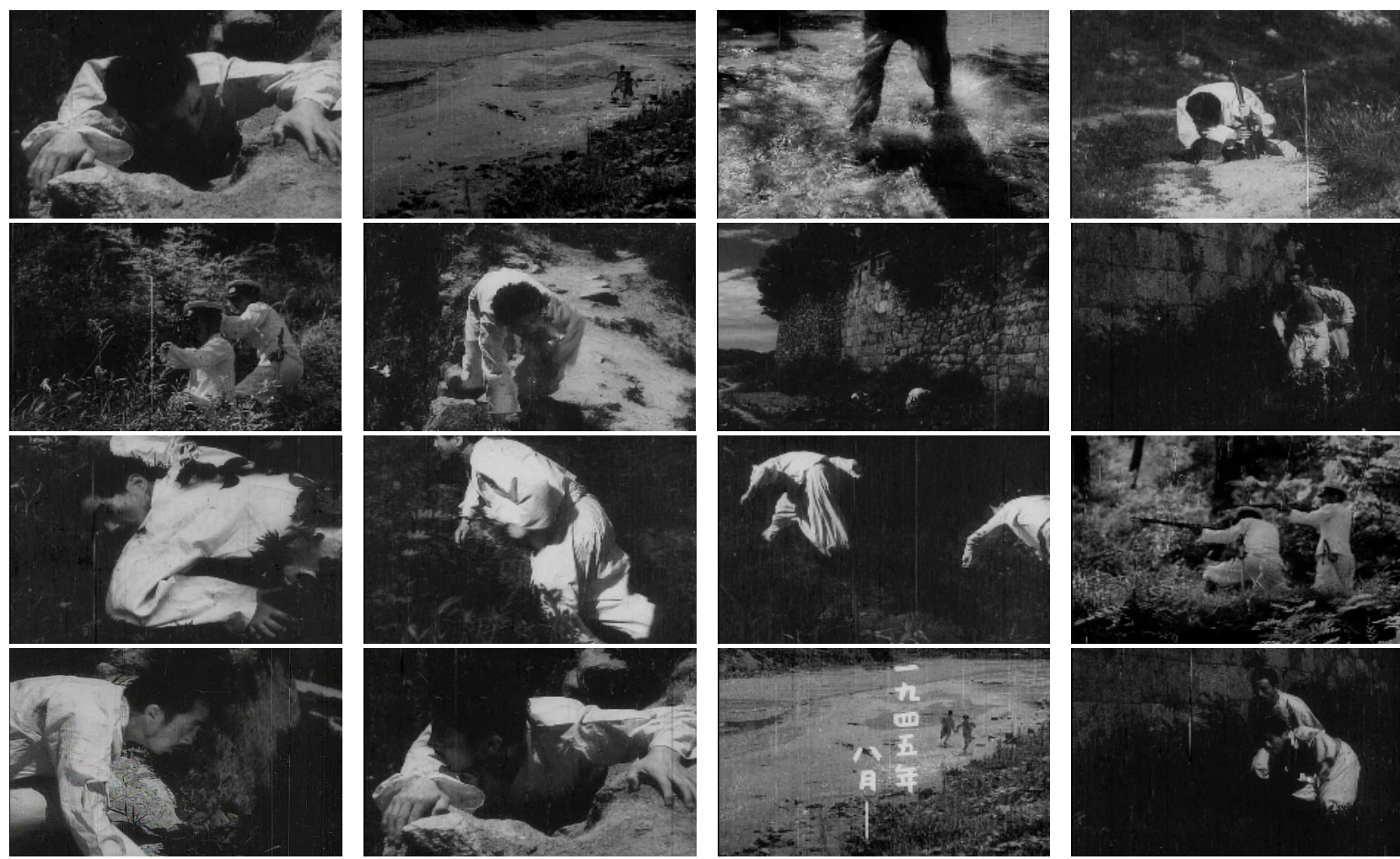

(Fig. 6) Test film scenes \#1- \#16 (left to right) from Viva Freedom
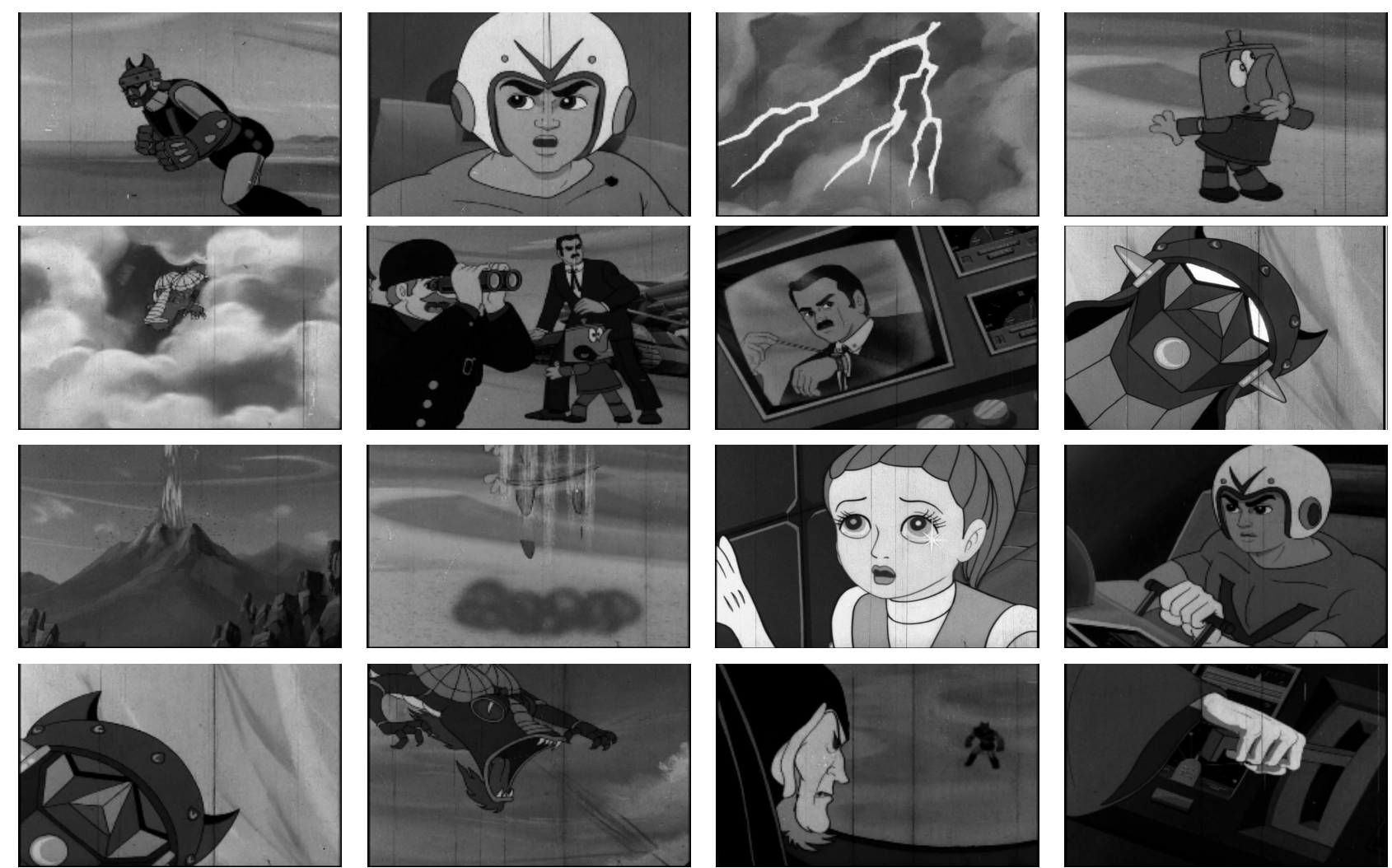

(Fig. 7) Test film scenes \# 1- \#16 (left to right) from Robot Taekwon V

location of each frame is manually detected by Blob Editor Tool that is an image authoring tool developed along with the inpainting application. The AR inpainting functionality utilizes degraded frame and its blob location 


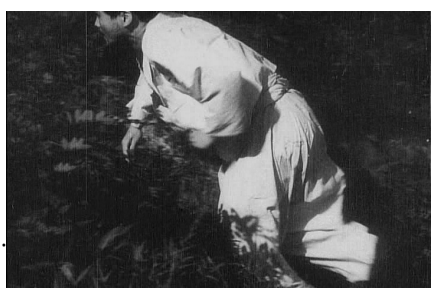

(a) Original frame \# 10

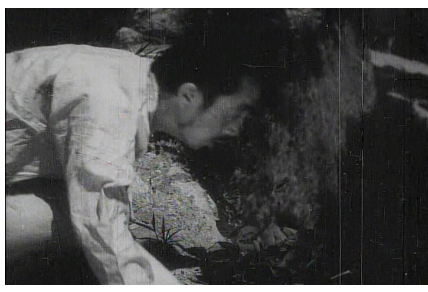

(b) Original Frame \# 13

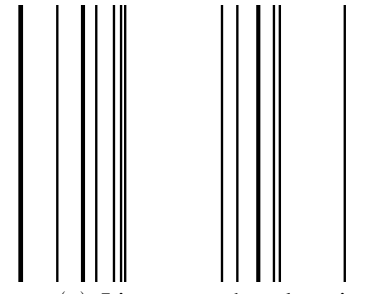

(c) Line scratches location

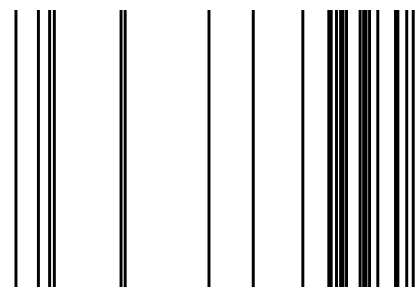

(c) Line scratches location

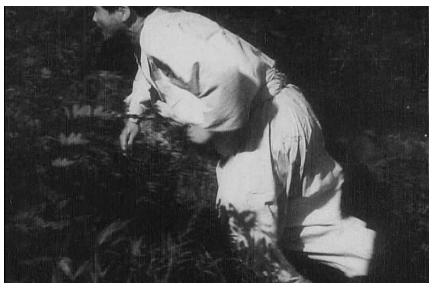

(e) Restored frame

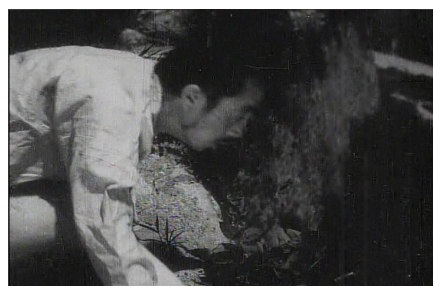

(e) Restored frame

(Fig. 8) Restored frames (\#10 and \#13) in Viva Freedom

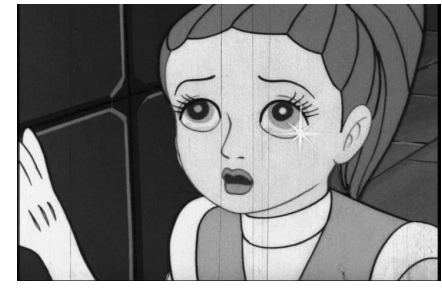

(a) Original frame \# 11

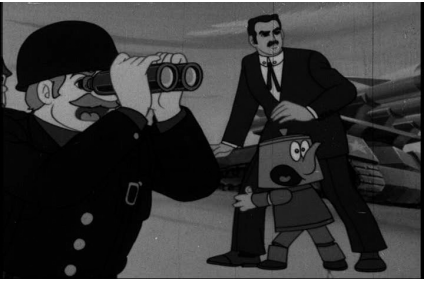

(b) Original Frame \# 6

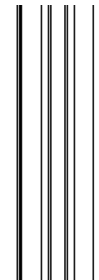

(c) Line scratches location

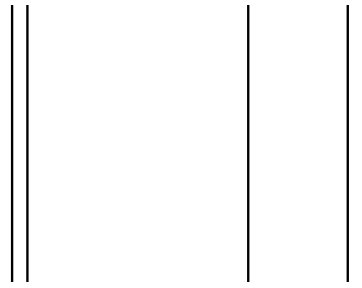

(c) Line scratches location

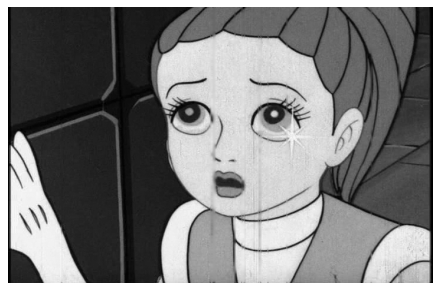

(e) Restored frame

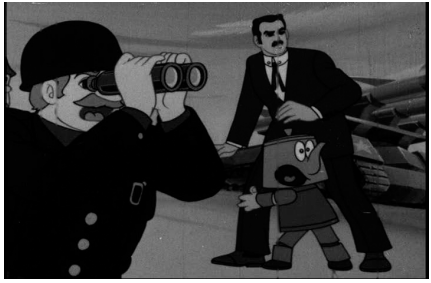

(e) Restored frame

(Fig. 9) Restored frames (\#11 and \#6) in Robot Taekwon V

as input to restoration process that results in inpainted frames. Results from our proposed algorithm are compared with Bertalmio's in subjective (MOS) and objective

〈Table 2〉 SOPHISTICATED MODE: PSNR results

\begin{tabular}{|c|c|c|c|c|}
\hline Film & \multicolumn{2}{|c|}{ Viva Freedom } & \multicolumn{2}{c|}{ Robot Taekwon V } \\
\hline Frame \# & Proposed & Bertalmio & Proposed & Bertalmio \\
\hline 1 & 35.15 & 34.42 & 34.70 & 20.30 \\
\hline 2 & 44.29 & 44.69 & 44.52 & 41.65 \\
\hline 3 & 43.22 & 43.09 & 46.12 & 31.69 \\
\hline 4 & 38.63 & 38.87 & 39.49 & 37.10 \\
\hline 5 & 38.14 & 37.46 & 41.73 & 40.16 \\
\hline 6 & 50.10 & 49.69 & 37.08 & 36.27 \\
\hline 7 & 45.03 & 44.38 & 47.10 & 36.82 \\
\hline 8 & 33.74 & 32.66 & 41.69 & 38.47 \\
\hline 9 & 46.27 & 44.87 & 48.25 & 48.29 \\
\hline 10 & 40.90 & 40.05 & 46.44 & 46.55 \\
\hline 11 & 40.58 & 40.29 & 37.77 & 36.66 \\
\hline 12 & 38.17 & 38.02 & 41.01 & 40.67 \\
\hline 13 & 36.03 & 35.61 & 38.35 & 38.12 \\
\hline 14 & 41.92 & 37.12 & 41.35 & 41.76 \\
\hline 15 & 41.80 & 41.57 & 43.66 & 43.88 \\
\hline 16 & 33.74 & 33.31 & 25.27 & 27.51 \\
\hline
\end{tabular}

quality (PSNR). <Table 2> and <Table $3>$ show PSNR and $\mathrm{RR}$ (restoration ratio) comparison results of 32

〈Table 3〉SOPHISTICATED MODE: Restoration Ratio (RR) results

\begin{tabular}{|c|c|c|c|c|}
\hline Film & \multicolumn{2}{|c|}{ Viva Freedom } & \multicolumn{2}{c|}{ Robot Taekwon V } \\
\hline Frame \# & Proposed & Bertalmio & Proposed & Bertalmio \\
\hline 1 & 9.82 & 12.33 & 60.17 & 14.27 \\
\hline 2 & 15.06 & 13.94 & 16.75 & 15.45 \\
\hline 3 & 11.29 & 12.36 & 21.83 & 11.55 \\
\hline 4 & 8.34 & 7.73 & 13.79 & 11.87 \\
\hline 5 & 5.47 & 3.95 & 16.48 & 14.01 \\
\hline 6 & 13.10 & 10.78 & 9.75 & 9.97 \\
\hline 7 & 15.03 & 10.34 & 16.23 & 11.23 \\
\hline 8 & 9.05 & 6.42 & 26.28 & 12.52 \\
\hline 9 & 14.51 & 15.02 & 15.66 & 14.77 \\
\hline 10 & 12.12 & 10.79 & 21.49 & 14.40 \\
\hline 11 & 6.02 & 7.73 & 8.03 & 8.19 \\
\hline 12 & 33.68 & 9.36 & 12.28 & 8.10 \\
\hline 13 & 6.29 & 4.04 & 14.59 & 12.52 \\
\hline 14 & 9.84 & 8.72 & 26.96 & 17.17 \\
\hline 15 & 11.85 & 11.52 & 17.41 & 16.42 \\
\hline 16 & 7.89 & 7.73 & 11.72 & 10.87 \\
\hline
\end{tabular}


restored frames, respectively. MOS test was done with the participation of 5 persons who were invited to see and give their opinion on 32 restored frames of "Viva Freedom" and "Robot Taekwon V" films by using Bertalmio and proposed algorithms. After collecting opinion scores we compute the arithmetic mean for each frame as shown in $\langle$ Table 4$\rangle$.

〈Table 4〉 Mean Opinion Score (MOS) results

\begin{tabular}{|c|c|c|c|c|}
\hline Film & \multicolumn{2}{|c|}{ Viva Freedom } & \multicolumn{2}{c|}{ Robot Taekwon V } \\
\hline Frame \# & Proposed & Bertalmio & Proposed & Bertalmio \\
\hline 1 & 3.60 & 3.20 & 3.20 & 2.60 \\
\hline 2 & 3.20 & 3.40 & 3.00 & 2.40 \\
\hline 3 & 3.20 & 3.40 & 3.00 & 2.00 \\
\hline 4 & 3.40 & 3.60 & 2.20 & 1.80 \\
\hline 5 & 3.80 & 2.80 & 2.00 & 1.80 \\
\hline 6 & 3.60 & 3.60 & 3.20 & 2.60 \\
\hline 7 & 3.80 & 3.20 & 3.80 & 3.00 \\
\hline 8 & 4.20 & 3.40 & 3.60 & 3.20 \\
\hline 9 & 3.80 & 3.80 & 3.80 & 2.60 \\
\hline 10 & 3.40 & 3.40 & 3.80 & 3.00 \\
\hline 11 & 3.20 & 3.00 & 2.80 & 2.00 \\
\hline 12 & 4.40 & 3.80 & 2.40 & 1.80 \\
\hline 13 & 3.60 & 2.80 & 1.20 & 1.20 \\
\hline 14 & 3.80 & 3.20 & 3.20 & 2.40 \\
\hline 15 & 3.60 & 3.20 & 3.00 & 2.80 \\
\hline 16 & 2.20 & 1.80 & 3.20 & 2.60 \\
\hline Average & $\mathbf{3 . 5 5}$ & $\mathbf{3 . 2 3}$ & $\mathbf{2 . 9 6}$ & $\mathbf{2 . 3 6}$ \\
\hline
\end{tabular}

\section{Conclusions}

We used designated sampling layout for pixel sampling, Durbin-Levinson algorithm with recursive computation for estimating model parameters and forecasting techniques for interpolation process. AR model can be articulated in our scheme to yield good reconstruction. We then implemented our old film restoration system over Texas Instruments DSP board TMS320DM642 EVM. We experimented with two Korean old films: "Viva Freedom" (1946) and "Robot Taekwon V" (1976), and the results show better elimination of degradations than Bertalmio's approach both in subjective quality (MOS test) and objective quality (PSNR and newly defined measure RR).

\section{References}

[1] M. Bertalmio, G. Sapiro, V. Caselles, and C. Ballester. "Image Inpainting," In Proc. SIGGRAPH 2000, 2000, pp.417-424.

[2] PrestoSpace project, http://prestospace.org.

[3] D. Vitulano, V. Bruni, and P. Ciarlini, "Line scratch detection on digital images: an energy based model," (Special Issue in) Journal of WSCG, Vol.10, No.2, 2002, pp.477-484.
[4] A. C. Kokaram, "Detection and removal of line scratches in degraded motion picture sequences," Signal Processing VIII, Vol.1, pp.5-8, Sep., 1996.

[5] A. C. Kokaram, "Motion Picture Restoration: Digital Algorithms for Artefact Suppression in Degraded Motion Picture Film and Video," Springer-Verlag, Berlin, Germany, 1998.

[6] M. Oliveira, B. Bowen, R. McKenna, and Y.-S. Chang. "Fast Digital Image Inpainting," In Proc. VCIP 2001, 2001, pp. 261-266.

[7] A. Telea. "An Image Inpainting Technique Based on the Fast Marching Method," Journal of Graphics Tools, Vol.9, No.1, pp.25-36, 2004.

[8] K. H. Ko and S. W. Kim. "Efficient Inpainting of Old Film Scratch using Sobel Edge Operator based Isophote Computation," in CIT 2006, 2006, pp.125.

[9] A. C. Kokaram, "A statistical framework for picture reconstruction using AR models," In European Conference on Computer Vision workshop on Statistical methods in video processing (ISBN 0-9581044-0-9),Copenhagen, Denmark, pp.73-78, June 2002.

[10] D. Marr and E. Hildreth, "Theory of edge detection," In Proc. Roy. Soc., London B207, 1980, pp.187-217.

[11] D. Mumford and J. Shah, "Optimal approximations by piecewise smooth functions and associated variational problems," In Comm. Pure Appl, Math, 42, 1989, pp.577-685.

[12] Texas Instruments Incorporated, http://www.ti.com.

[13] Peter J. Brockwell (Author), Richard A. Davis (Author), "Introduction to Time Series and Forecasting," Springer, New York, 1996.

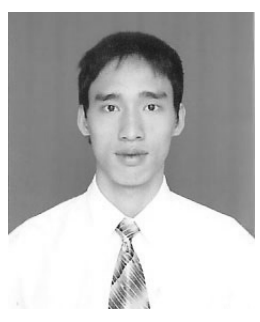

\section{한 녹 손}

e-mail : han.ngoc.son@gmail.com

2006년 Hanoi University of Technology Applied Mathematics(학사)

2009년 서울시립대학교 컴퓨터통계학과(석사) 2009년 현 재 한국전자통신연구소 연구원 관심분야: $\mathrm{WSN}$, 영상복원, 게임기술

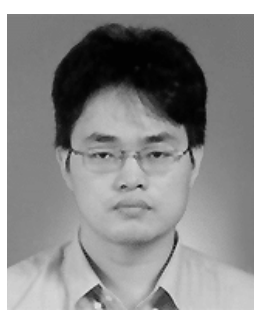

\section{김 성 환}

e-mail :swkim7@uos.ac.kr

1999년 한국과학기술원 전자전산학과(박사) 1996 2000년 LG정보통신 이동통신연구소 선임연구원

2000 2002년 Cisco Systems EWBU Senior Research Engineer

2002년 현 재 서울시립대학교 컴퓨터과학부 부교수 관심분야: 컴퓨터 보안, 영상통신, 무선멀티미디어, 게임기술 